\title{
Use of Percutaneous Ethanol Injection Therapy for Recurrent Secondary Hyperparathyroidism after Subtotal Parathyroidectomy
}

\author{
Walter G. Douthat, ${ }^{1}$ Gabriela Cardozo, ${ }^{1}$ Gabriela Garay, ${ }^{2}$ Santiago Orozco, ${ }^{3}$ \\ Carlos Chiurchiu, ${ }^{1}$ Jorge de la Fuente, ${ }^{1}$ Javier de Arteaga, ${ }^{1}$ and Pablo U. Massari ${ }^{1}$ \\ ${ }^{1}$ Bone and Mineral Metabolism Section, Renal Service, Hospital Privado-Centro Médico de Córdoba, \\ Postgraduate School of Nephrology, Catholic University of Córdoba, Naciones Unidas 346, 5016 Córdoba, Argentina \\ ${ }^{2}$ Clinical Chemistry Laboratory, Hospital Privado-Centro Médico de Córdoba, 5016 Córdoba, Argentina \\ ${ }^{3}$ Department of Radiology, Hospital Privado-Centro Médico de Córdoba, 5016 Córdoba, Argentina
}

Correspondence should be addressed to Walter G. Douthat, wdouthat@hospitalprivadosa.com.ar

Received 20 December 2010; Revised 31 March 2011; Accepted 4 April 2011

Academic Editor: Alessandro Amore

Copyright (C) 2011 Walter G. Douthat et al. This is an open access article distributed under the Creative Commons Attribution License, which permits unrestricted use, distribution, and reproduction in any medium, provided the original work is properly cited.

We evaluated the efficacy of percutaneous ethanol injection therapy (PEIT) as a therapeutic option for recurrence of secondary hyperparathyroidism after subtotal parathyroidectomy in ESRD patients. Six patients underwent PEIT. A mean of $1.3 \pm 0.8$ ethanol injections was performed. Nodular volume was $1.5 \pm 1.7 \mathrm{~cm}^{3}$, and $2.8 \pm 2.8 \mathrm{~cm}^{3}$ of ethanol was injected per patient. After ethanol injection PTH decreased significantly $(1897 \pm 754$ to $549 \pm 863 \mathrm{pg} / \mathrm{mL}(P<.01))$. There was also a reduction in serum calcium, phosphorus and calcium-phosphorus product. A positive and significant correlation was found between nodular volume with ethanol injected and time from parathyroidectomy. Only one patient required hospitalization due to severe hypocalcaemia. In other two cases, local discomfort and temporary mild dysphonia were registered. PEIT is an effective treatment to control recurrences of secondary hyperparathyroidism postsubtotal parathyroidectomy.

\section{Introduction}

Medical treatment is the main strategy to control secondary hyperparathyroidism in patients with end-stage renal disease (ESRD). However, in many cases this condition becomes refractory to drug therapy [1]. For this reason, invasive procedures such as intranodular ethanol injection (percutaneous ethanol injection therapy, PEIT) or parathyroidectomy have been proposed $[2,3]$. The type of procedure used depends of the intact PTH levels, number and size of the glands involved, and their ultrasonographic visibility.

In the case of subtotal parathyroidectomy, patient keeps between $1 / 4$ and $1 / 2$ of the gland. Over time, if the conditions causing hyperparathyroidism persist, gland may grow and increase again the levels of intact PTH. Moreover, after surgery a high percentage of patients (12 to 30\%) may develop recurrent or persistent hyperparathyroidism [4]. Thus, the patient will suffer the clinical consequences of hyperparathyroidism once again (i.e., high morbiditymortality), despite surgery. When the residual nodule is visible with ultrasonography, its destruction is possible with ethanol injection until the desired levels of intact PTH and calcium phosphorus product are reached [5].

We presented a series of patients with recurrent hyperparathyroidism postsubtotal parathyroidectomy who were adequately managed with PEIT.

\section{Subjects and Methods}

The study included six patients with ESRD under chronic hemodialysis and diagnosis of recurrent secondary hyperparathyroidism. All the patients had history of secondary hyperparathyroidism that became refractory to the medical treatment. Because, this condition, all patients had undergone subtotal parathyroidectomy with neck exploration searching for the four parathyroid glands and removing the 
TABle 1: Demographic and clinical data. Mean \pm SD.

\begin{tabular}{lc}
\hline Characteristic & Total patients $(N=6)$ \\
\hline Age to PEIT, years & $47.4 \pm 11.1$ \\
Gender, female/male & $3 / 3$ \\
Time from HD to PTx, months & $82.0 \pm 44.0$ \\
Time from PTx to PEIT, months & $26.4 \pm 45.7$ \\
\hline
\end{tabular}

ESRD: end-stage renal disease, HD: hemodialysis, PEIT: percutaneous ethanol injection treatment, and PTx: parathyroidectomy.

three glands that were macroscopically more affected and the $1 / 2$ or $3 / 4$ part of the gland with healthier aspect. No autotransplantation of parathyroid tissue was performed in any of the cases.

The indication of the treatment with PEIT was recurrent secondary hyperparathyroidism with levels of intact PTH higher than $300 \mathrm{pg} / \mathrm{mL}$ in patients who had undergone a subtotal parathyroidectomy and presence of at least one parathyroid nodule visible in the ultrasonography.

The mean age of the population was $47.4 \pm 11.1$ years (median 47, min 36-max 64), 3 patients were female, and the mean time elapsed from the initiation of hemodialysis therapy to the PEIT was $108.4 \pm 58.6$ months (median 89, min 36-max 180). Three patients had ESRD secondary to chronic glomerulonephritis, one case was associated to eclampsia, and other two; the cause of ESRD was unknown.

Before PEIT, medical management for hyperparathyroidism included control of hyperphosphatemia with a low phosphorous diet, oral phosphate binders (calcium, sevelamer, and aluminum), more intensive dialysis and in cases without contraindications oral/iv calcitriol. Similar measures were used after PEIT in order to maintain an adequate calcium-phosphorus metabolism and to avoid recurrence of hyperparathyroidism.

2.1. Study Procedures. All injections were administered by the same qualified interventional radiologist and performed under ultrasonographic guidance. Nodular volume and size of all glands treated with PEIT were larger than $0.1 \mathrm{~cm}^{3}$ as calculated by ultrasonographic evaluation of their 3 longest axes. A 95\% ethanol solution was used for PEIT with a total alcohol volume calculated to be at least the same as the nodule volume. A modified needle for ethanol injection with small side holes, easily recognized under ultrasonography and local anesthesia with lidocaine in an ambulatory facility was used. The treatment was considered successful when the levels of intact PTH decreased from 150 to $300 \mathrm{pg} / \mathrm{mL}$, as suggested by K/DOQI guidelines [6]. Major and minor complications related to the proceeding were registered in each patient. All the patients sign the informed consent in order to carry out the procedure.

2.2. Biochemical Measurements. Biochemical assays were performed immediately before the first PEIT session (basal) and between 1 and 7 days after the last PEIT session (final).

Serum creatinine, calcium, phosphorus, and alkaline phosphatase were measured with an autoanalyzer (Hitachi
917: Hitachi, Ltd., Tokyo, Japan), and intact iPTH by electrochemiluminescence (Nichol's Institute, San Juan Capistrano, Calif, USA).

2.3. Statistical Analyses. Results are expressed as mean \pm standard deviation. Statistical analysis for continuous variables was performed with Wilcoxon nonparametric test. Correlations between variables were calculated according to Pearson's coefficient. A value of $P<.05$ was considered as significant.

\section{Results}

All patients had a residual parathyroid nodules identified by ultrasonography, and PEIT was performed $26.4 \pm 45.7$ months (median 7, min 2-max 108), after parathyroidectomy (Table 1).

In one patient, an ectopic parathyroid gland located in anterosuperior mediastinum behind the manubrium was detected. This patient had undergone parathyroid surgery twice. In the first surgery, 3 parathyroid glands were removed, and in the second surgery some months later, glandular tissue was not identified. The patient did not accept to undergo another surgery when an ectopic parathyroid gland was detected by scintigraphy. In the remaining 5 patients, the ultrasonography detected residual and enlarged parathyroid tissue in the site where a small portion of parathyroid gland had been left during the surgical procedures.

In average, $1.3 \pm 0.8$ ethanol injections were made per patient and a mean of $2.8 \pm 2.8 \mathrm{~cm}^{3}$ of ethanol was injected. The average nodular volume was $1.5 \pm 1.7 \mathrm{~cm}^{3}$, although the volumes were very different among patients $\left(0.2\right.$ to $\left.4.5 \mathrm{~cm}^{3}\right)$ (Table 2).

The mean levels of PTH had a significant decrease at final control, falling from $1897 \pm 754$ to $549 \pm 863 \mathrm{pg} / \mathrm{mL}$ $(P<.01)$ (Figure 1$)$.

The average decrease of intact PTH was $72 \pm 33 \%$ (range $8,0-96,6 \%)$. There was also a decrease in the levels of serum calcium, phosphorus, and calcium-phosphorus product, being significant in the last two. A positive and significant correlation was found between the total nodular volume, the volume of ethanol used in each session $(r=0.85 ; P<.02)$, and the time from parathyroidectomy $(r=0.87 ; P<.02)$ (Figure 2).

In one patient, the expected result on intact PTH decrease was not achieved. This patient showed a reduction of $8 \%$ in the level of PTH and maintained the levels of calcium and phosphorus above the recommended level by K/DOQI guidelines after PEIT [6]. This procedure was performed on a small nodule of only $0.2 \mathrm{~cm}^{3}$, and PEIT had to be stopped prematurely due to technical problems to visualize and identify the parathyroid nodule. Ectopic gland was not found by a scintigraphy.

When analyzing the degree of compliance with the parameters of mineral metabolism recommended by K/DOQI guidelines (intact PTH, calcium, phosphorus, and $\mathrm{Ca} \times \mathrm{P}$ product), it was observed that prior to the PEIT, no patients were in agreement with the 4 parameters; 2 patients meet 3 criteria, 2 patients fulfill only one, and the 


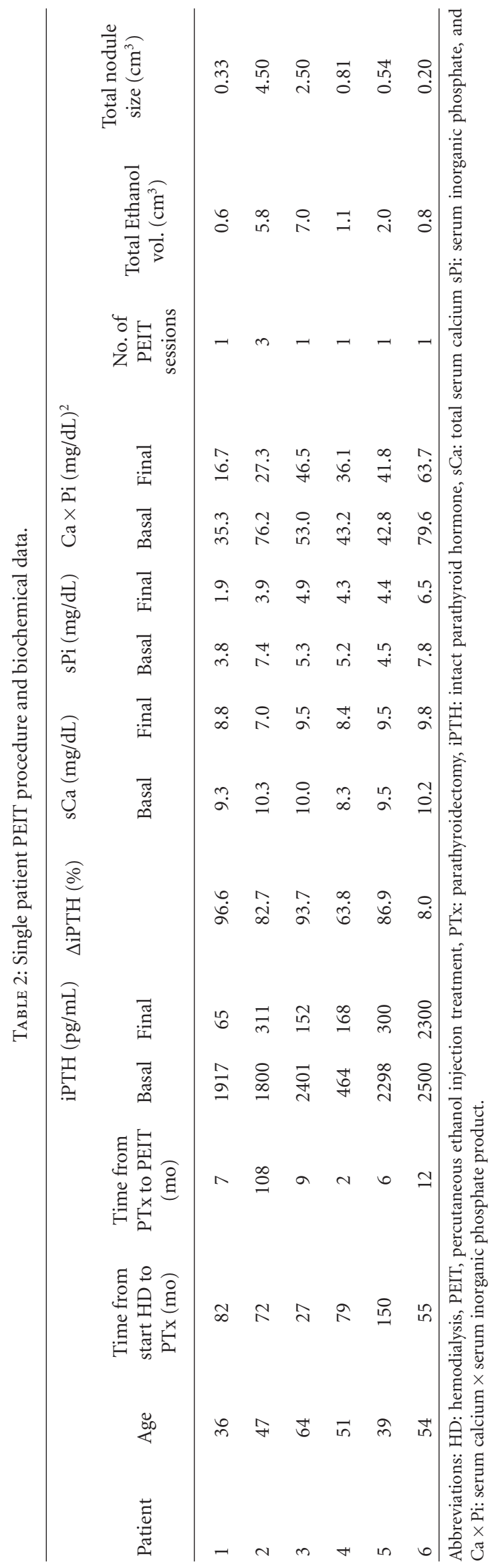




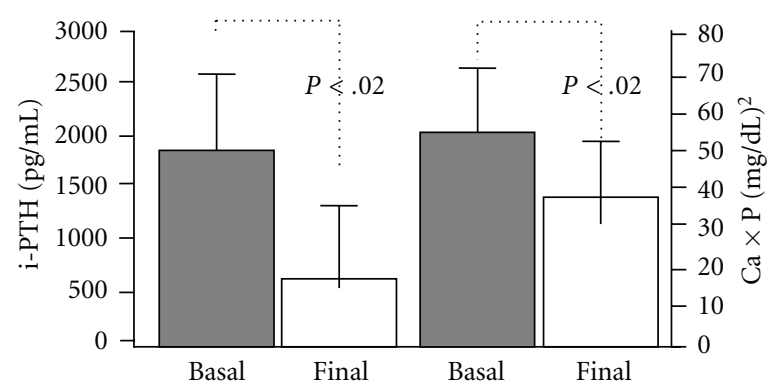

(a)

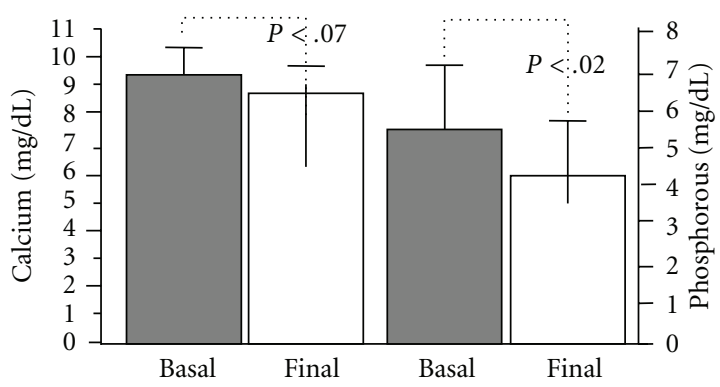

(b)

FIGURE 1: Intact parathyroid hormone, calcium, phosphate, and calcium $\times$ phosphorous product levels pre- and post-PEIT.

remaining 2 patients did not satisfy any of the recommended parameters. At the final control post-PEIT, one patient meet the 4 criteria, 4 patients fulfill 3 criteria, while the remaining patient did not satisfy any of the parameters recommended by K/DOQI [6]. This last patient was the one who did not properly respond to PEIT (Table 2).

All the procedures were performed on an outpatient basis, and only one patient required hospitalization after the procedure due to severe hypocalcaemia that reverted with calcium replacement by intravenous administration. In two cases, only local discomfort and temporary mild dysphonia were registered.

\section{Discussion}

In several clinical settings, severe secondary hyperparathyroidism can be controlled quickly and safely by using PEIT. This technique is not only an alternative to surgical parathyroidectomy, but also an important adjunct to medical management [7]. It has proved to be useful for patients either on dialysis or after renal transplantation in circumstances in which the disease is considered to be resistant to medical treatment or when the surgical risk is high [8-10].

Secondary hyperparathyroidism is a common complication of the long-term dialysis $[11,12]$. The DOPPS international study has demonstrated that $26.3 \%$ of the patients from the participant countries have hyperparathyroidism [13]. It has been shown to predominate in Latin American countries $[12,14]$.

Secondary hyperparathyroidism is managed successfully with medical treatment in most of the patients, but the

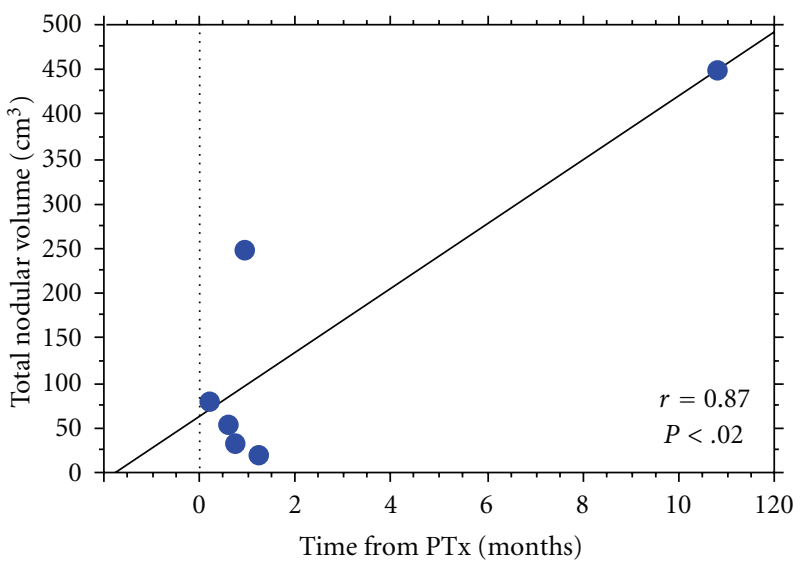

(a)

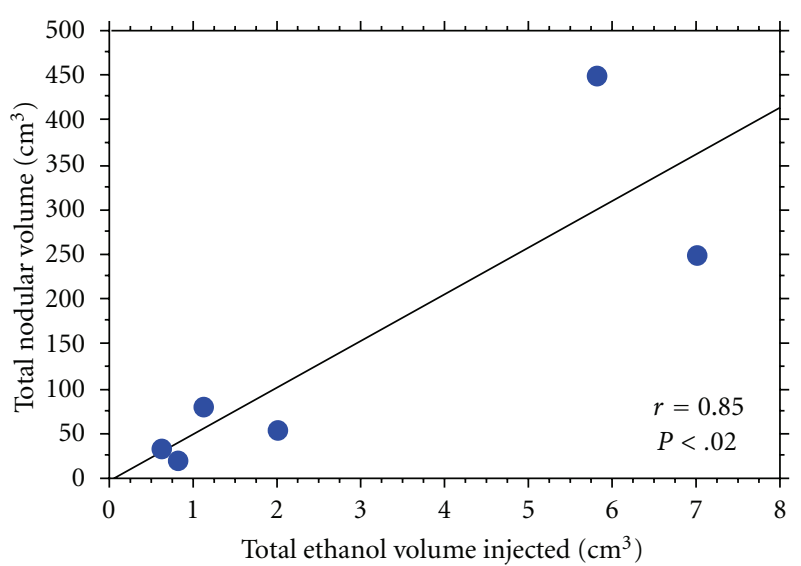

(b)

Figure 2: Correlation between total nodular volume, total volume of ethanol used, and the time from parathyroidectomy (PTx).

disease becomes refractory to the therapy in a considerable number of them [1]. These is more frequent in subjects with severe, long-term hyperparathyroidism and with nodular hyperplasia in enlarged glands. This glands have a lowerdensity receptors for calcitriol and calcium both needed to respond to the treatment $[1,15]$. Therefore, in these patients, it is necessary to consider the possibility of using invasive treatment [2].

Surgical parathyroidectomy is indicated when the patients who do not respond to the medical treatment present signs of osteitis fibrosa, extraosseous calcifications, hypercalcemia or hyperphosphatemia, with more than 2 glands visible with ultrasonography, and dramatically increased levels of intact PTH $[16,17]$. Although in most of the patients there is an important decrease of PTH levels, a considerable number of them ranging from 10 to $30 \%$ suffer a recurrence of secondary hyperparathyroidism, and it is required, in many cases, to undergo more complicated reoperations [18].

Potential factors related with recurrent postsurgical hyperparathyroidism are the persistence of the conditions causing hyperparathyroidism such as the presence of a 
residual portion of parathyroid gland, which is present when either a subtotal or a total parathyroidectomy with autotransplantation is performed. In rare cases, an ectopic gland that was not obvious in presence of the other activated parathyroid glands may evidence increased size and activity. Once recurrence occurred, the levels of PTH will dramatically increase again with their known consequences on the skeleton and cardiovascular system. The therapeutic possibilities of these cases are reduced. These residual nodules are refractory to the medical treatment because they do not have the adequate concentration of both calcium and calcitriol receptors [19]. A new surgical procedure implies some risks because of the high morbidity of these patients, some technical complications in a sector with a previous surgery that usually presents periglandular fibrosis and with the only possibility of removing all the residual parathyroid tissue, which causes hypoparathyroidism in most of the cases.

In the patients of the present series, surgical resection of the remnant parathyroid tissue was not recommended due to a high risk to produce severe and permanent hypoparathyroidism causing adynamic bone disease with cardiovascular calcifications. Cryopreservation of parathyroid tissue is an option to prevent this complication but the technique is not available in our center.

In some cases, Lomonte et al. have described the successful use of cinacalcet inducing the suppression of intact PTH secretion by the parathyroid glands [20]. However, in order to achieve this aim, it is necessary to have an adequate quantity of calcium receptors in the remaining parathyroid tissue, which is not the rules in cases of secondary hyperparathyroidism refractory to the medical treatment [19]. Although cinacalcet represents a valid option for these patients, it is not available for use in many countries, for example, in Latin America countries.

Since the early 1980s, PEIT has been proposed as a less invasive alternative to parathyroidectomy [21]. The basis of this therapy is that enlarged parathyroid glands with nodular hyperplasia are destroyed selectively by ethanol injection [22]. We recently reported in dialysis patients a significant decrease in $\mathrm{PTH}$, with improvement in serum calcium, phosphate, and $\mathrm{Ca} \times \mathrm{P}$ product. These results were significantly correlated with PTH levels and nodular volume [9]. Patients under dialysis, with large nodule volume and very high PTH levels, obtained good results after PEIT [9].

Failure to PEIT could be related to a wrongly selection of gland for ethanol injection. Poor results have been obtained in glands with difficult accessibility, diffuse hyperplasia, ectopic glands, and ultrasonographic poor visibility such as in the case of patient number 6 .

It has also proved to be useful in cases of hyperparathyroidism after renal transplantation, complicated with hypercalcemia and hypophosphatemia with few and minor complications. In this setting, parathyroidectomy is considered too aggressive for controlling the hyperparathyroidism, and was carries out [10].

At the present, there are no data about the use of PEIT in patients with recurrent hyperparathyroidism after subtotal parathyroidectomy, so that this is the first series of patients reporting this technique in this setting [5].
All the patients included in this study suffered from a severe secondary hyperparathyroidism and had previously undergone at least one subtotal parathyroid surgery. After PEIT, the level of intact PTH showed a significant decrease with a mean rate of $72 \%$. Four patients reached levels of intact PTH within the parameters recommended by K/DOQI guidelines. In one case, the level was close to the suggested value with $311 \mathrm{pg} / \mathrm{mL}$ and in the remaining patient no adequate response was achieved (Table 2).

In summary, as it was previously demonstrated for patients undergoing dialysis and transplantation, PEIT has proved to be a useful technique for the management of recurrent postsurgical secondary hyperparathyroidism. It was useful to rapidly resolve a common complication of parathyroidectomy at a low cost and with a high level of safety. Results of the present series suggest that PEIT should be considered for the treatment of recurrent postsurgical secondary hyperparathyroidism particularly when calcimimetic and cryopreservation are not available. Prospective and controlled trials comparing PEIT with others therapies are needed to confirm their role in the management of this disease.

\section{Acknowledgment}

This work was supported for research in part by Fundación Nefrológica de Córdoba, Argentina.

\section{References}

[1] M. Fukagawa, N. Fukuda, H. Yi, and K. Kurokawa, "Resistance of parathyroid cell to calcitriol as a cause of parathyroid hyperfunction in chronic renal failure," Nephrology Dialysis Transplantation, vol. 10, no. 3, pp. 316-319, 1995.

[2] M. Fukagawa and S. Nakanishi, "Role of parathyroid intervention in the management of secondary hyperparathyroidism," Nephrology Dialysis Transplantation, vol. 18, supplement 3, pp. 23-26, 2003.

[3] H. Ogata, M. Mizobuchi, F. Koiwa, E. Kinugasa, and T. Akizawa, "Clinical significance of parathyroid intervention on CKD-MBD management," NDT Plus, vol. 1, supplement 3, pp. 9-13, 2008.

[4] Y. Tominaga, "Surgical management of secondary hyperparathyroidism in uremia," American Journal of the Medical Sciences, vol. 317, no. 6, pp. 390-397, 1999.

[5] S. Yumita, "Intervention for recurrent secondary hyperparathyroidism from a residual parathyroid gland," Nephrology Dialysis Transplantation, vol. 18, supplement 3, pp. 62-64, 2003.

[6] National Kidney Foundation, "K/DOQI clinical practice guidelines for bone metabolism and disease in chronic kidney disease," American Journal of Kidney Diseases, vol. 42, supplement 3, pp. S1-S201, 2003.

[7] M. Tanaka and M. Fukagawa, "Medical management after parathyroid intervention," NDT Plus, vol. 1, supplement 3, pp. 18-20, 2008.

[8] F. Koiwa, T. Hasegawa, R. Tanaka, and T. Kakuta, "Indication and efficacy of PEIT in the management of secondary hyperparathyroidism," NDT Plus, vol. 1, supplement 3, pp. 14-17, 2008.

[9] W. G. Douthat, S. E. Orozco, J. de Arteaga, and P. Massari, "Treatment of refractory secondary hyperparathyroidism with 
ethanol injection: the importance of glandular volume," Kidney International, vol. 63, supplement 85, pp. S101-S104, 2003.

[10] W. G. Douthat, S. Orozco, P. Maino et al., "Percutaneous ethanol injection therapy in post-transplant patients with secondary hyperparathyroidism," Transplant International, vol. 20, no. 12, pp. 1031-1035, 2007.

[11] D. Sherrard, G. Hercz, Y. Pei et al., "The spectrum of bone disease in end-stage renal failure, an evolving disorder," Kidney International, vol. 43, no. 2, pp. 436-442, 1993.

[12] W. G. Douthat, G. Garay, J. de Arteaga, J. L. Fernández Martín, J. B. Cannata Andía, and P. U. Massari, "Espectro bioquímico e histológico de la osteodistrofia renal en Argentina," Nefrología, vol. 23, supplement 2, pp. 47-51, 2003.

[13] E. W. Young, T. Akiba, J. M. Albert et al., "Magnitude and impact of abnormal mineral metabolism in hemodialysis patients in the dialysis outcomes and practice patterns study (DOPPS)," American Journal of Kidney Diseases, vol. 44, supplement 2, pp. 34-38, 2004.

[14] V. Jorgetti, B. D. López, H. Caorsi et al., "Different patterns of renal osteodystrophy in Iberoamerica," American Journal of the Medical Sciences, vol. 320, no. 2, pp. 76-80, 2000.

[15] E. Ritz, "Which is the preferred treatment of advanced hyperparathyroidism in a renal patients: early parathyroidectomy should be considered as the first choice," Nephrology Dialysis Transplantation, vol. 9, pp. 1816-1821, 1994.

[16] R. Jofré, J. M. López Gómez, J. Menárguez et al., "Parathyroidectomy: whom and when?" Kidney International, vol. 63, supplement 85, pp. S97-S100, 2003.

[17] Y. Tominaga, "Current status of parathyroidectomy for secondary hyperparathyroidism in Japan," NDT Plus, vol. 1, supplement 3, pp. 35-38, 2008.

[18] A. De Francisco, G. F. Fresnedo, E. Rodrigo, C. Piñera, J. A. Amado, and M. Arias, "Parathyroidectomy in dialysis patients," Kidney International, vol. 61, supplement 80, pp. 161-166, 2002.

[19] N. Fukuda, H. Tanaka, Y. Tominaga, M. Fukagawa, K. Kurokawa, and Y. Seino, "Decreased 1,25-dihydroxyvitamin D3 receptor density associated with a more severe from of parathyroid hyperplasia in chronic uremic patients," Journal of Clinical Investigation, vol. 92, no. 3, pp. 1436-1443, 1993.

[20] C. Lomonte, M. Antonelli, N. Losurdo, G. Marchio, B. Giammaria, and C. Basile, "Cinacalcet is effective in relapses of secondary hyperparathyroidism after parathyroidectomy," Nephrology Dialysis Transplantation, vol. 22, no. 7, pp. 20562062, 2007.

[21] L. Solbiati, A. Giangrande, R. Pra et al., "Ultrasound-guided percutaneous fine-needle etanol injection into parathyroid glands in secondary hyperparathyroidism," Radiology, pp. 155-607, 1985.

[22] A. Giangrande, A. Castiglioni, L. Solbiati, E. Ballarati, and F. Caligara, "Chemical parathyroidectomy for recurrence of secondary hyperparathyroidism," American Journal of Kidney Diseases, vol. 24, no. 3, pp. 421-426, 1994. 


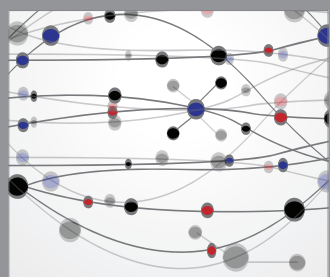

The Scientific World Journal
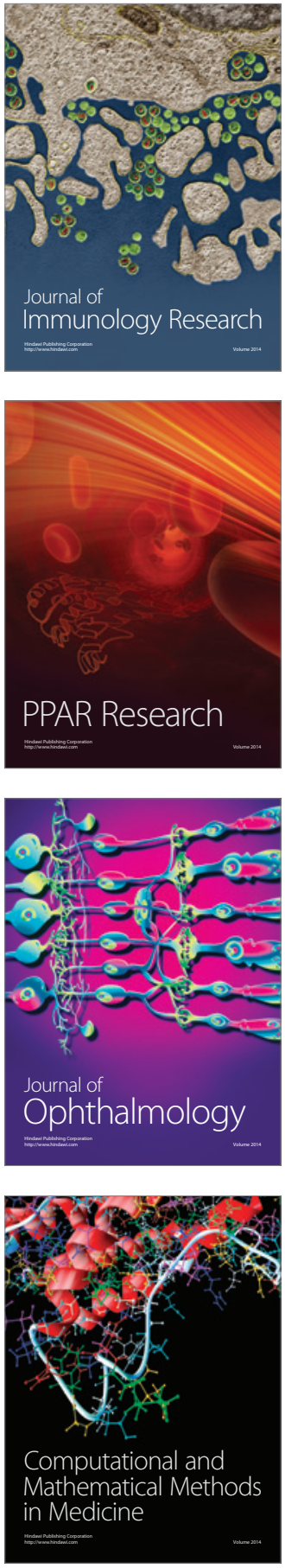

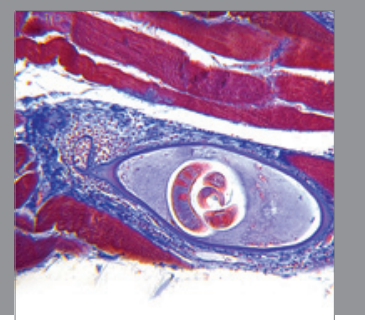

Gastroenterology

Research and Practice
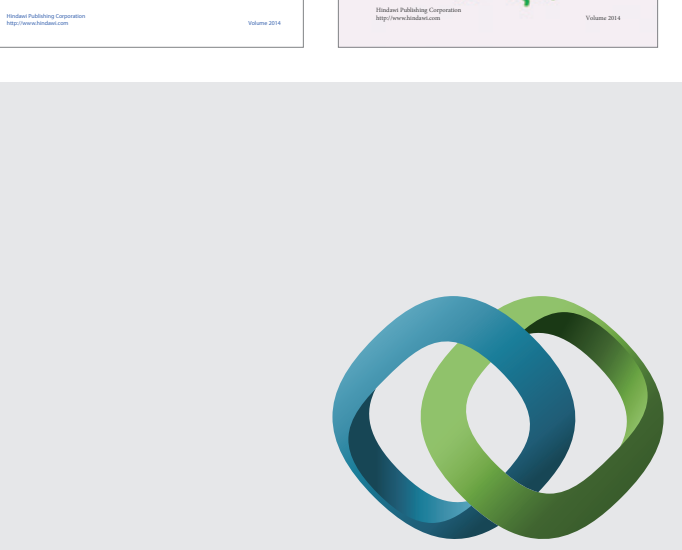

\section{Hindawi}

Submit your manuscripts at

http://www.hindawi.com
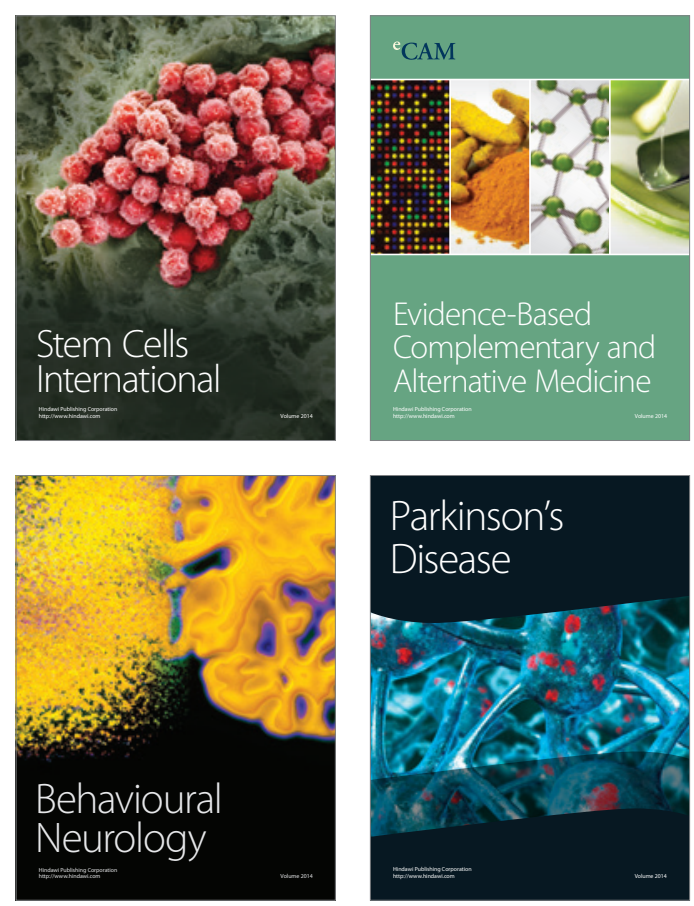

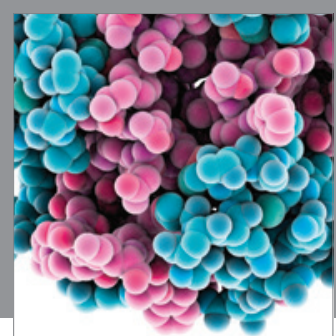

Journal of
Diabetes Research

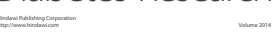

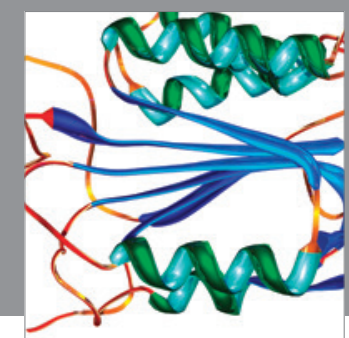

Disease Markers
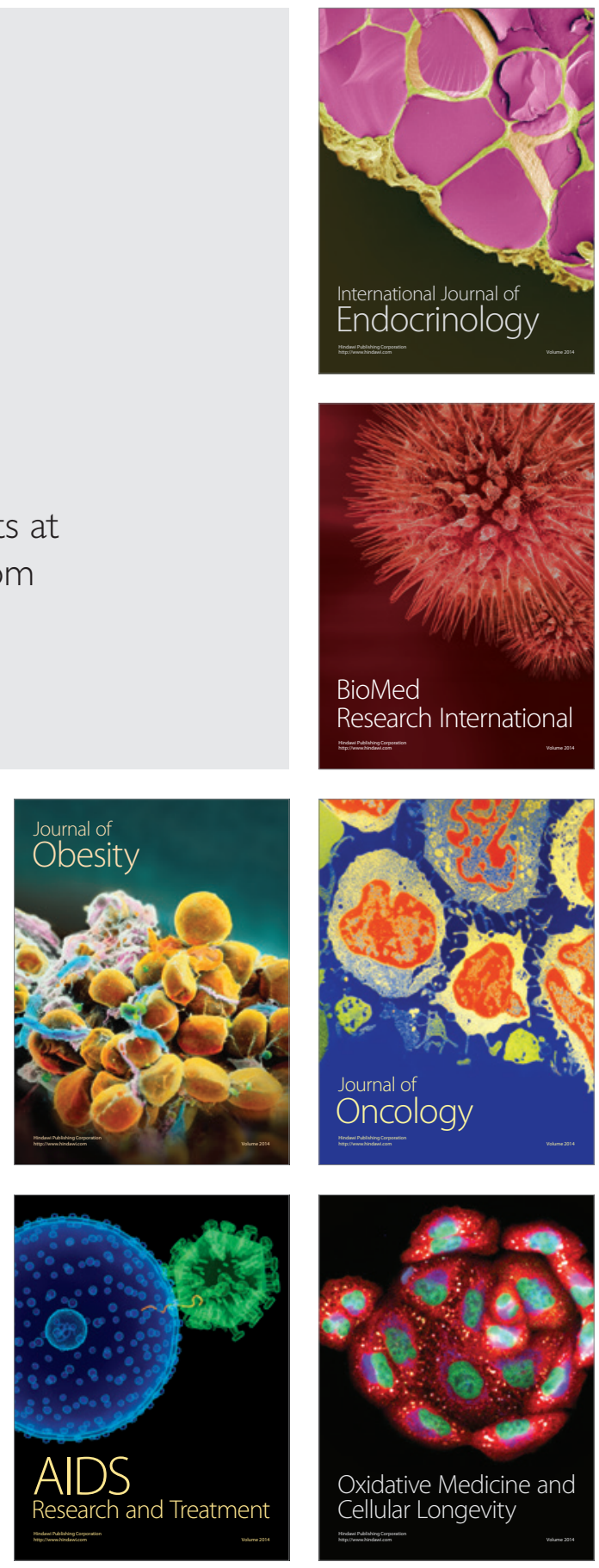